\title{
Opinions and intentions of parents of an autistic child toward genetic research results: two typical profiles
}

\author{
Laurence Baret ${ }^{1}$ and Beatrice Godard ${ }^{\star 1}$
}

Returning results to research participants is increasingly acknowledged in research ethics guidelines. But few research teams actually do it or provide mechanisms for offering it as an option. We explored the perspective of parents of an autistic child participating in genetic research. In all, 388 questionnaires were sent to 194 parents; 158 questionnaires were completed ( 89 mothers and 69 fathers), giving a response rate of $41 \% .97 \%$ of respondents $(n=153)$ fully expressed a strong desire to receive research results, either general or individual ones. The survey solicited parents' opinions as to what means could be put in place to return research results. The majority held the research team responsible for returning individual results (79.7\%, $n=126)$. They indicated that it should occur at the completion of the research project $(69 \%, n=109)$, by mail $(75.3 \%, n=119)$. Over three quarters felt the Ministry of Health should cover the associated costs $(77.8 \%, n=123)$. If the communication of individual findings, whether positive or negative, were to be possible, these would allow some respondents 'to be prepared for the future' $(37 \%, n=57)$, without necessarily having practical benefits $(21 \%, n=32)$, but at least bringing them 'relief or understanding' (14\%, $n=21)$. Moreover, parents were clear about the difference between research and clinical settings. This study underlines the importance of broadening the discussion about the communication of research results, especially individual ones. We believe that the integration of different perspectives - those of researchers, clinicians, ethics committees and participants - will enrich the debate and offer enlightenment for future ethical guidelines.

European Journal of Human Genetics (2011) 19, 1127-1132; doi:10.1038/ejhg.2011.106; published online 15 June 2011

Keywords: genetic research results; research ethics; disclosure; postal survey; research participants

\section{INTRODUCTION}

Genetics studies have become increasingly prevalent, leading to a large body of information on disease susceptibility, with the potential to improve health care. ${ }^{1}$ Although some of the data can be characterized as exploratory, that is to say, non-validated or hypothesis generating, with no clinical utility, there is a growing international trend for research participants to be offered access to their personal research data if they choose to see it. ${ }^{2-4}$ The guidelines governing research with human subjects are relatively extensive with respect to clinical trials. ${ }^{2}$ Researchers have a duty to return the results if the latter meet three criteria: scientific validity, clinical relevance and benefits to the participant. ${ }^{4}$ This framework, however, does not help in a context of exploratory results, such as in genetics. ${ }^{5}$ In such a context, how to envisage the return of research results? Researchers are facing the issue of whether to follow this trend, and if so, how research participants might receive the results? and more particularly if they can receive individualized results. ${ }^{3,6}$ But what are the attitudes and needs of research participants themselves? There is very little empirical data on this. ${ }^{2,7-9}$

It is important to note that this article does not address the return of incidental findings picked up during routine data cleaning and data analyses. Most incidental findings cannot be directly correlated with a particular disease or condition. Even if researchers may incidentally identify genetic abnormalities that might influence the clinical care of an individual, it is beyond the aims of their study. Unlike research results which are data obtained as part of the research protocol to answer a given study question, most incidental findings are not information anticipated from the study and cannot be generalized for a wide or general application.

Ravitsky and Wilfond (2006) report two main approaches concerning the return of research results. The first one focuses on research with a reluctance to return results for three main reasons: the potential harm to participants ${ }^{10-12}$ budgetary constraints surrounding such a practice ${ }^{13}$ and lack of practical guidance in the guidelines. ${ }^{14}$ The second one focuses on the autonomy of the participant and considers the return of research results as a 'moral imperative.' ${ }^{15}$ This vision is conveyed by the guidelines for research involving humans in which the obligation of the researcher to return results to participants that wish it ${ }^{4,16}$ is increasingly common. But these guidelines are unclear on the desired practical achievements, such as what type of information should be returned? By whom? When? How? and Who is to bear the cost? ${ }^{4}$ Such vagueness leaves research teams puzzled. Although they are aware of this emerging ethical issue, they do not know how to return research results to study participants, and they do not know about participants' wishes in this respect. In this paper, we present empirical data on one set of participants' expectations, as well as their needs and concerns about the return of research results. Data were gathered using a postal survey of parents of an autistic child having participated in a genetic research project on autism.

\section{SUBJECTS AND METHODS}

Study participants

An ethical approval was obtained from the regional Research Ethics Committee (Centre de recherche du centre hospitalier de l'Université de Montréal or

\footnotetext{
1Department of Social and Preventive Medicine, Faculty of Medicine, Université de Montréal, Montréal, QC, Canada

*Correspondence: Professor B Godard, Department of Social and Preventive Medicine, University of Montreal, C.P. 6128, Succursale Centre-Ville, Montreal, QC, Canada H3C 3J7. Tel: +1 514343 6832; Fax: +1 514343 2371; E-mail: beatrice.godard@umontreal.ca

Received 11 January 2011; revised 31 March 2011; accepted 3 May 2011; published online 15 June 2011
} 
CR-CHUM). Consent to participate in the study was presumed upon receipt of a completed questionnaire.

Data used in this paper originate from a genetic research on autism in which no individual result was communicated. According to the database provided, 194 families were eligible to participate in our survey. The information letter accompanying the survey indicated that it was independent of the genetic study, and although no individual result was given out, our study aimed to obtain research participants' point of view on the return of information in research projects, so as to analyze the perceived risks and benefits related to the communication of either general or individual findings. Respondents were asked to fill out an anonymous questionnaire and each parent was specifically asked to fill one out. A reminder was sent to all 194 families 4 weeks after the original mail-out.

We sent 388 questionnaires to the 194 eligible families (to the mother and the father). In all, 158 questionnaires were filled out ( 89 mothers and 69 fathers) and sent back to us resulting in a response rate of $41 \%$ after one reminder. Due to the fact that the questionnaire was anonymous, it was impossible to know in how many families each parent filled out the questionnaire. In all, $92.4 \%$ of respondents indicated that they live with a spouse, but they did not mentioned if the spouse was the parent of the child enrolled in the genetic study; $7 \%$ of respondents mentioned that they did not live with a spouse.

\section{Study instrument}

Our anonymous postal questionnaire was validated by researchers in the fields of genetics and research ethics, by parents of autistic children and by different actors working with children with mental retardation in order to empirically test the reliability of the questionnaire.

The questionnaire took $\sim 30 \mathrm{~min}$ to fill out. A first section aimed to contextualize the respondents' experience in a research setting (why did they participate in the genetic study? what were the advantages and disadvantages they envisioned for themselves and for their child? what importance did they accord to genetics? and what they knew about the return of research results?). Their attitudes toward participation in genetic studies and their expectations about the return of 'general' or 'individual' results were also discussed in this part of the questionnaire. The terminology used in our study as explained to research participants is summarized in Table 1 . The next section of the questionnaire inquired as to their views on their wish to receive, or not, research results (what kind of information they wanted? what benefits they envisioned, from whom they wanted to receive information? when? who should bear the expense of result dissemination? what they thought they would do with the information? and what impact they thought the return of research results would have on their lives?). Finally, the last part documented the sociodemographic data of the participants.

\section{Statistical analysis}

Information from the completed questionnaires was transferred to an Excel database. Coding and analysis were conducted using the Statistical Package for Social Sciences (SPSS) software v. 16.0 (http://www.spss.com). A descriptive analysis documented the expectations of participants as well as providing avenues to address the practical issues of returning research results to participants. The interpretative analysis, based on $\chi^{2}$ and factorial analyses, allowed us to better characterize the respondents and to reach a deeper analysis of what motivated and guided their choices. Factorial correspondence analysis is an inductive exploration of a data set for finding patterns in the data when several traits have been recorded for each individual. ${ }^{17}$ By reducing the number of primary traits into a smaller number of factors that are combinations of the original variables and that account for the most variance, the redundancy in the original data set is eliminated, and true associations between traits may be found. In regard to our sample, a factorial correspondence analysis was carried out to identify and quantify distinct components in the respondents' population based on their responses to the survey questions. A typological analysis was also carried out to determine the main characteristics of respondent groupings toward the return of individual research results. We considered a $P$-value of 0.05 or less as statistically significant.

\section{RESULTS}

The characteristics of the respondents are given in Table 2. Of the 158 completed questionnaires, fathers filled out 69 , mothers 89 . Even if respondents were informed that no individual result concerning their child would be disclosed, $97 \%$ of them $(n=153)$ still indicated a wish to be informed of individual research results, whether favorable or not.

\section{Opinions}

Given that an important concern of researchers and ethics committees is the impact on participants of receiving unfavorable individual findings, our analysis focused on the comparison of expectations and needs of research participants toward the reception of a general finding $v s$ an unfavorable individual finding (Figure 1). The vast majority of respondents indicated that the research team should take on the responsibility of communicating results $(85 \%$ for general results and $80 \%$ for unfavorable individual ones), rather than a health professional or a research ethics committee. Another finding was that although the participants wanted to obtain results, they did not expect to act to get them. A majority of respondents indicated that the best time to receive the results would be at the end of the research project (respectively $78 \%$ for a general result and $69 \%$ for an unfavorable individual result) and before the results were made public. It seems important for them to get the information, acquired thanks to them, before any dissemination to a wider public. Again, respondents did not expect to contact the research team to receive the results. As a matter of fact, they would not know when to do so. As shown in Figure 1, the preference to receive research results such as they were had priority over that of receiving them only once validated and before a prevention or a treatment became available. The favored means of communication was via mail for any type of result (75\% for an unfavorable individual result), much higher than by going to a clinic. This finding challenges the ethical guidelines governing research according to which disclosure of personal information should preferably be done during a face-to-face meeting. Finally, the vast

Table 1 Terminology for the types of result

\begin{tabular}{ll}
\hline Result type & Definition \\
\hline General findings & Overall findings drawn from the scientific conclusions of the research project, based on the entire group of participants \\
Favorable individual findings & $\begin{array}{l}\text { Findings which are specific to the genetic make-up of each participant. For the purpose of our study, by favorable individual } \\
\text { finding, we mean a result indicating that no genetic mutation has been identified in the autistic child within the framework of } \\
\text { the research into Pervasive Developmental Disorders }\end{array}$ \\
Unfavorable individual findings & $\begin{array}{l}\text { Findings which are specific to the genetic make-up of each participant. For the purpose of our study, a unfavorable individual } \\
\text { finding is a result indicating that a genetic mutation has been identified in the autistic child within the framework of the research } \\
\text { into Pervasive Developmental Disorders }\end{array}$ \\
\hline
\end{tabular}


Table 2 Characteristics of the respondents $(n=158)$

\section{Age}

Sex

Living with a spouse

Number of children

Number of dependent children

Education level

Revenue
40 years and under (22.8\%); 41-50 (48.7\%); 51 years and over (27.8\%); missing data $(0.7 \%)$

$56.3 \%$ female $/ 43.7 \%$ male

Yes (92.4\%); no (7.0\%); missing data (0.6\%)

1 (7.6\%); 2 (58.2\%); 3 (27.8\%); 4 and more (5.7\%); missing data $(0.7 \%)$

0 (6.3\%); 1 (21.5\%); 2 (43.7\%); 3 (22.8\%); 4 (2.5\%); missing data (3.2\%)

No schooling (0\%); elementary/high school (32.9\%); college (19.6\%); university (46.8\%); missing data (0.7\%)

Under $\$ 20000$ (5.1\%); $\$ 20000$ to under $\$ 40000$ (10.8\%); $\$ 40000$ to under $\$ 60000$ (22.8\%); $\$ 60000$ to under $\$ 80000$ (15.8\%); $\$ 80000$ to under $\$ 100000$ (13.3\%); $\$ 100 ، 000$ and over (23.4\%); missing data (8.8\%)

Individuals charged with communicating findings

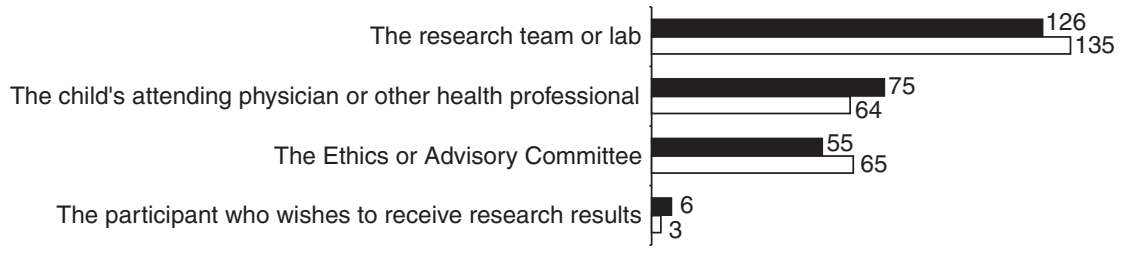

Moment to receive the information

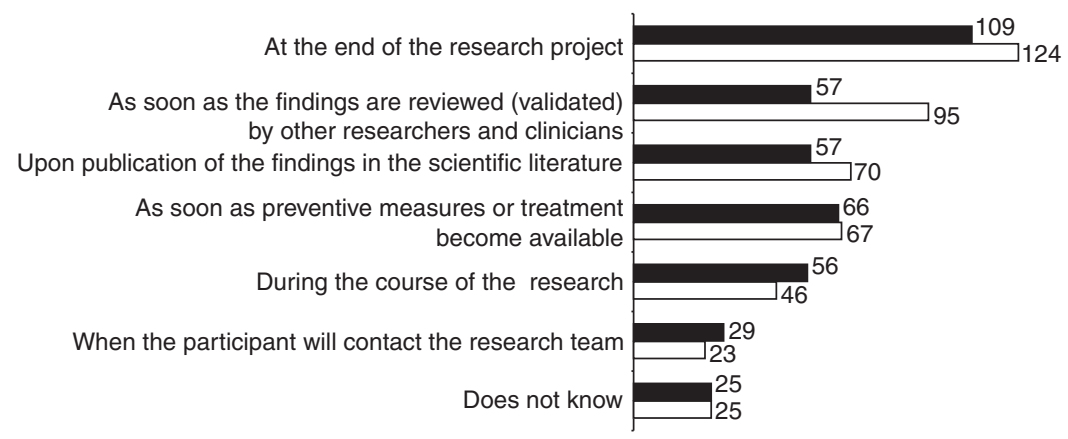

Means of communicating findings

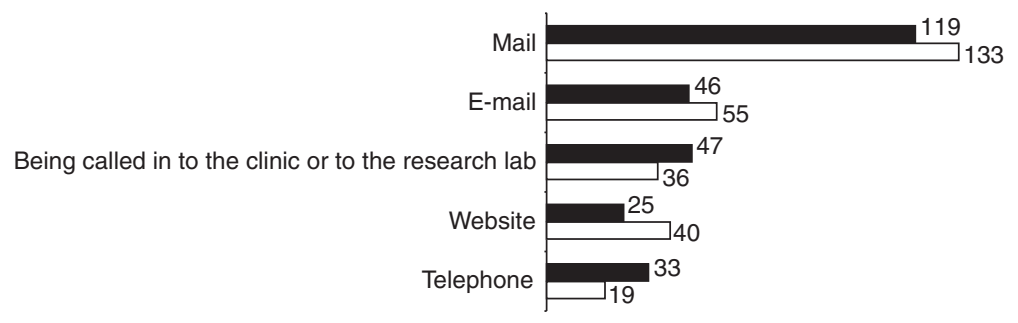

Costs borne by

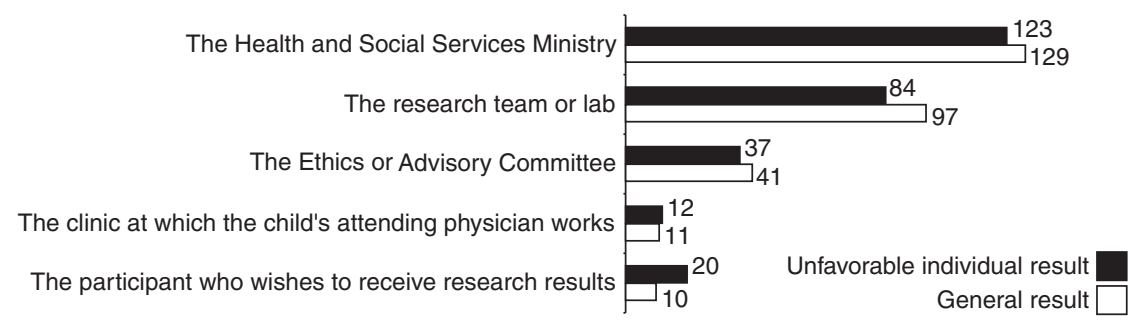

Figure 1 Preferences regarding the return of research results, depending on the type of result, reported by parents of autistic children ( $n=158$ ).

majority of respondents indicated that the costs associated with the return of research results should be covered by the Ministry of Health and Social Services (78\% for an unfavorable individual result), neither the research team nor the research ethics board, much less the doctor of the child.

\section{Intentions}

Two points of particular interest were, first, the participants' perceptions of the expected impact on them of receiving individual information, and second, what the participants thought they would do with such information, if available, whether favorable or unfavorable. While 


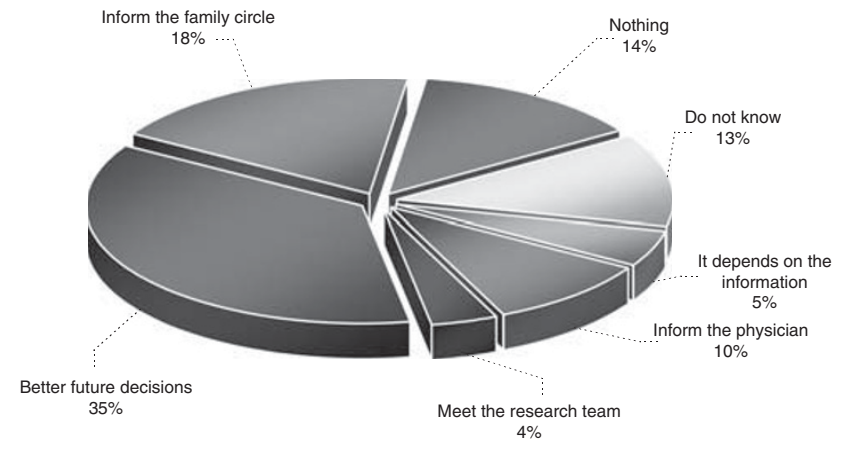

Figure 2 What the respondent expects to do with an individual finding.

a consensus emerged as to the desired means to be used to return research results, there was a great diversity of views on the two previous points.

To the open question 'If the communication of individual findings turns out to be possible (whether positive or negative), what would you expect to do with this information?', less than half of the respondents indicated that the communication of individual findings would allow them to make better decisions for the future $(37 \%, n=57)$, or would allow them to inform their family circle $(19 \%, n=29)$ (Figure 2). In all, $14 \%$ of respondents $(n=21)$ even indicated that they would do nothing with the information, although they still would like to receive it. Although the respondents vary on how they would use such results, their expectations seemed to be realistic.

The same plurality of opinions appears regarding the expected impact of the results on each respondent's life or on their child's life (Figure 3). If the communication of individual findings turns out to be possible, whether favorable or unfavorable, those findings would allow some respondents 'to be prepared for the future' $(37 \%, n=57)$, without necessarily having an impact $(21 \%, n=32)$, but at least bringing relief or understanding $(14 \%, n=21)$. All in all, the perceived impact seems either positive or neutral.

\section{Two typical profiles}

With the diversity of intentions expressed by respondents and in spite of unanimous views favoring the return of research results, whether favorable or unfavorable, a factor analysis brought out two typical profiles in favor of returning individual research results (Figure 4): (a) a profile of persons concerned by a possible transmission of autism and (b) a profile of persons who 'want to know'. The first profile (a), representing $20 \%$ of the respondents, will make practical use of the research results, that is, they will prepare for the future, including making reproductive choices accordingly. The expectations of this group contrast with those of the other profile (b), which represents $15 \%$ of the respondents. They participated in the study for the sole purpose of knowing, with no associated intentions. In fact, respondents in this group participated in the research project to contribute to the advance of scientific knowledge.

Following the characterization of these patterns, other profiles were searched for in order to understand who would make what use of research results once these were obtained. Due to concerns in the literature on the therapeutic misconception ${ }^{18,19}$ we defined a 'clinical profile', that is people who take part in research with clinical expectations (to get treatment for their child or a clinical follow-up). This clinical profile was not present in a significant way among the respondents, indicating that the latter (1) do not seem to have

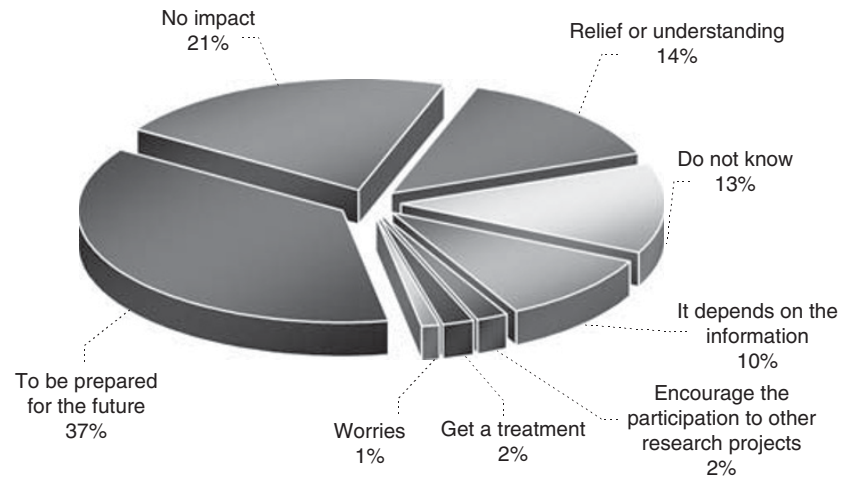

Figure 3 The impact an individual finding could have on the respondent's life.

unrealistic clinical expectations and (2) do not confuse the clinical setting with the research setting.

\section{DISCUSSION}

Our study gathered empirical data from participants in an ongoing genetic research project on autism involving children and their parents. These data may help in broadening the discussion about the communication of research results, especially individual, unfavorable ones.

Noting an unanimous desire to receive individual research results, whether favorable or unfavorable, with varying intentions about subsequent action, from 'doing nothing' to preparing for the future, everyone was nonetheless clear about the difference between research and clinical settings. In that context, we reviewed the literature in search of arguments for and against the communication of research results (Table 3 ). The most common argument deals with the potential harm of receiving an unfavorable individual result, particularly one of uncertain clinical value. ${ }^{3}$ In our study, respondents did not perceive any potential harm, even if they were listed in the questionnaire. They rather saw the benefits. Some authors have mentioned a paternalistic attitude in researchers. ${ }^{20}$ Our results indicate that research participants are able to balance the risks and benefits of research, as they do not have unrealistic clinical expectations. Indeed, if one accepts to participate in a research project and is judged sufficiently autonomous to do so, it seems paradoxical that their autonomy cannot be recognized at the end of the study. Ironically, the argument that a research participant may not be able to understand the results is often put forward in the literature. Certain authors, like Brand, consider that 'the scientific community will lose credibility if, on one hand, it is promoting research literacy and enabling and empowering individuals for informed decision making, while, on the other hand, ignoring and withholding genomics knowledge. ${ }^{20}$

A second argument is about the lack of resources, what with the limited means available to health-care systems. ${ }^{13,14,21}$ Although a lack of funds is the major obstacle to returning information, ${ }^{22}$ a real, practical evaluation of the supplementary allocation required to return research results has yet to be carried out. In our study, respondents preferred mail for communicating research results, whether favorable or unfavorable. With computerized databases, it becomes easier to manage and follow research participants. In cases where the communication of individual findings turns out to be possible, recontacting research participants would be doable. Other authors have suggested that a good approach would be to tell all participants, by means of generalized feedback, that a particular result has achieved clinical 


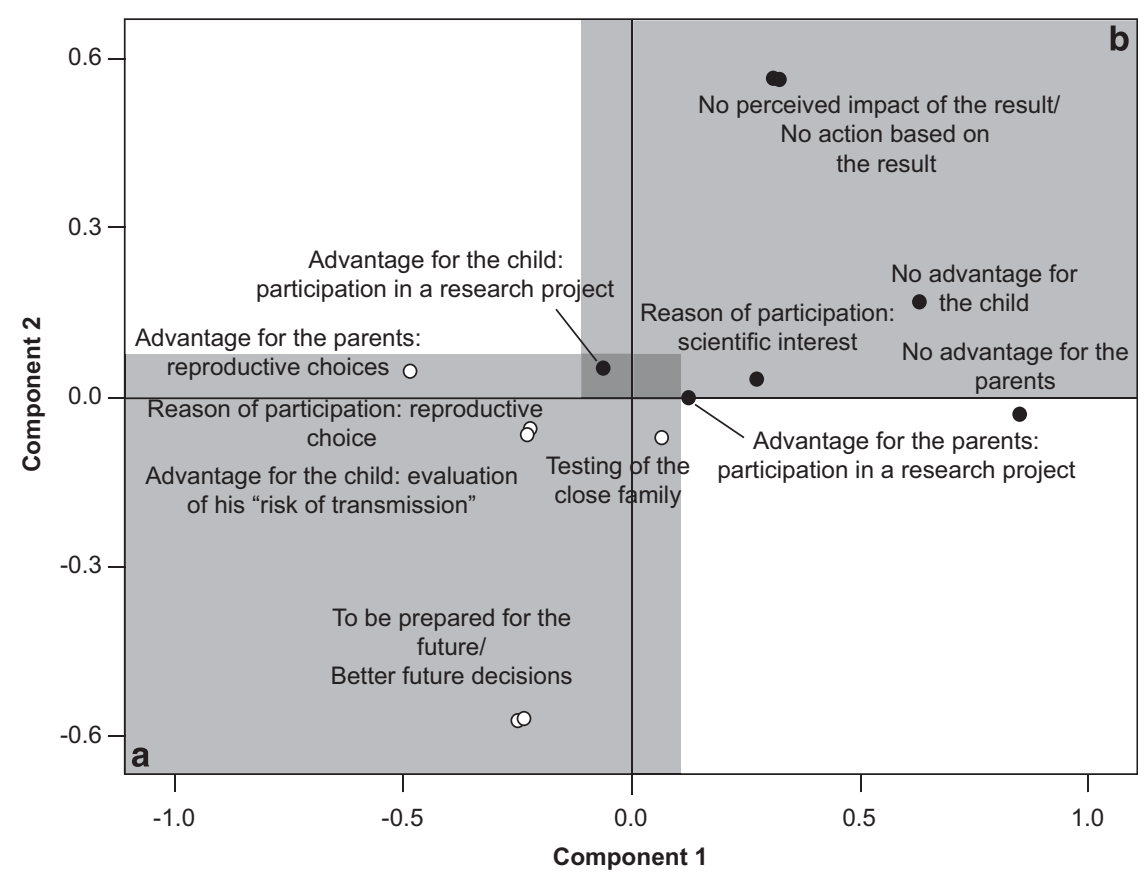

Figure 4 Characterization of two profiles: (a) profile of persons concerned by a possible transmission of autism and (b) profile of persons who want to know.

Table 3 Potential harm and benefits of communicating research results

\begin{tabular}{|c|c|}
\hline Potential harm & Potential benefits \\
\hline Increased stress or anxiety & $\begin{array}{l}\text { Recognition of an underlying reciprocity } \\
\text { that characterizes participation in a } \\
\text { research project }\end{array}$ \\
\hline Changing lifestyles & Desire to participate in other studies \\
\hline Reduction of future perspectives & $\begin{array}{l}\text { Increased awareness of autism or } \\
\text { genetic advances }\end{array}$ \\
\hline $\begin{array}{l}\text { Improper interpretation of results } \\
\text { leading to incorrect decisions or } \\
\text { causing harm }\end{array}$ & Better planning of the future \\
\hline Deterioration of relations with relatives & Reduction of uncertainty \\
\hline $\begin{array}{l}\text { Risk of stigmatization and } \\
\text { discrimination }\end{array}$ & $\begin{array}{l}\text { Assessment of the risk of 'transmission' } \\
\text { Informing family }\end{array}$ \\
\hline
\end{tabular}

significance and that they should consider seeking testing via a clinical geneticist. ${ }^{1,22}$

Last but not least, another argument against communicating research results is the lack of guidance in the ethical guidelines. We believe that the integration of different perspectives - such as those of researchers, clinicians, ethics committees and participants - will help in the debate. By identifying the specific needs, preferences and concerns of those various stakeholders, an integrative vision could emerge. To do so, more empirical studies are needed to understand the perspectives of various actors in different settings so as to mold ethical guidelines consistent with the reality of the practice.

\section{CONCLUSION}

This empirical study allows a better understanding of the opinions and intentions of research participants as to the communication of results. We note that the majority of respondents did not perceive a negative impact regarding the reception of research results, whatever those results were. In addition, they did not have unrealistic expectations. Consequently, is there still a benefit to withholding information? ${ }^{22}$ Can research participants have a right to be informed of research results, based on the right to self-governance, as Beauchamp and Childress state ${ }^{23}$ Although this question emerges in the literature, ${ }^{20,22,24}$ it might be premature to move directly from empirical data showing a strong desire of respondents to receive research results to a claim that participants have a right to receive their personal results.

However, concrete avenues can be explored concerning the return of research results, all the while minimizing the potential harm and enhancing respect for the participants and their central role in research:

- Offer the choice to research participants of receiving or not their personal research results, while specifying the nature of this information, throughout the study. This would respect their right to know or their right not to know.

- The potential benefits and possible harm linked to the reception of individual research results should be explained to the participant at the beginning of the study.

- An efficient and inexpensive way of returning research results to participants could be developed through a computerized database, a mailing list, etc, or, as suggested by Affleck, ${ }^{22}$ by means of a generalized feedback mechanism upon which participants could base themselves to seek testing via a clinical geneticist.

- A sharing of the responsibility to return research results between the research team and a clinician also seems important, since a large majority of respondents indicated they would like to report the result to their physician. This would respect the clinician/ researcher distinction and ensure that results were given by those best trained to do so. ${ }^{22}$

- One could envisage a sharing of costs between the research team, the funding agency and the Ministry of Health and Social Services. 
Research funds could be specifically allocated to the dissemination of research results (to the participants but also to the public in general) in a perspective of scientific disclosure and knowledge translation.

\section{Limitations}

The results and the analysis rely on self-reported data from the questionnaire. It may be possible that people who answered the survey were those who wanted the results, as it may be possible that parents with autistic children may have a hunger for any medical information, which could explain the very high percentage in favor of disclosure of research results. However, we also think that people who were totally against disclosure would have also wanted to answer the questionnaire, in order to emphasize their point of view.

In addition, the nature of the population studied - parents with autistic children - may limit the generalizability of our findings to other similar disorders and not reflect the full spectrum of current genetic research.

\section{CONFLICT OF INTEREST}

The authors declare no conflict of interest.

\section{ACKNOWLEDGEMENTS}

We would like to thank all the families who participated in this study. We are grateful to the Guy Rouleau's genetic research team for its help and support during the research process. Genome Quebec financially supported this study. The assistance of statisticians at the University of Montreal's SCMEQ (Service de consultation en méthodes quantitatives) was very useful in validating our results.

1 Fabsitz RR, McGuire M, Sharp RR et al: Ethical and practical guidelines for reporting genetic research results to study participants. Updated guidelines from a national heart, lung, and blood institute working group. Circ Cardiovasc Genet 2010; 3: 574-580.

2 Renegar G, Webster C, Stuerzebecher S et al: Returning genetic research results to individuals: Points to consider. Bioethics 2006; 20: 24-36.
3 Hayeems RZ, Miller FA, Li L, Bytautas JP: Not so simple: a quasi-experimental study of how researchers adjudicate genetic research results. Eur J Hum Genet 2011; e-pub ahead of print 16 March 2011; doi:10.1038/ejhg2011.34.

4 Knoppers BM, Joly Y, Simard J et al: The emergence of an ethical duty to disclose genetic research results: international perspectives. Eur J Hum Genet 2006; 14: 1170-1178.

5 Ravitsky V, Wilfond BS: Disclosing individual genetic results to research participants. Am J Bioeth 2006; 6: 8-17.

6 Bredenoord AL, Kroes HY, Cuppen E et al: Disclosure of individual genetic data to research participants: the debate reconsidered. Trends Genet 2010; 27: 41-47.

7 Rothstein MA: Tiered disclosure options promote the autonomy and well-being of research subjects. Am J Bioeth 2006; 6: 20.

8 Shalowitz DI, Miller FG: Disclosing individual results of clinical research: implications of respect for participants. JAMA 2005; 294: 737-740.

9 Murphy J, Scott J, Kaufman D et al: Public expectations for return of results from largecohort genetic research. Am J Bioeth 2008; 8: 36-43.

10 Case DO, Andrews JE, Johnson JD et al: Avoiding versus seeking: the relationship of information seeking to avoidance, blunting, coping, dissonance, and related concepts. J Med Libr Assoc 2005; 93: 353-362.

11 Dixon-Woods M, Jackson C, Windridge KC et al: Receiving a summary of the results of a trial: qualitative study of participants' views. Qualitative study of participants' views. BMJ 2006; 332: 206-210.

12 Meltzer LA: Undesirable implications of disclosing individual genetic results to research participants. Am J Bioeth 2006; 6: 28-30.

13 Fernandez CV, Skedgel C, Weijer C: Considerations and costs of disclosing study findings to research participants. CMAJ 2004; 170: 1417-1419.

14 Miller F, Christensen R, Giacomini M et al: Duty to disclose what? Querying the putative obligation to return research results to participants. J Med Ethics 2008; 34: 210-213.

15 Fernandez CV, Kodish E, Weijer C: Informing study participants of research results: an ethical imperative. IRB 2003; 25: 12-19.

16 Fernandez CV: Public expectations for return of results - Time to stop being paternalistic. Am J Bioeth 2008; 8: 46-48.

17 Benzecri J-P: Correspondence Analysis Handbook. New York: Marcel Dekker, 1992.

18 Miller F, Giacomini M, Ahern C et al: When research seems like clinical care: a qualitative study of the communication of individual cancer genetic research results. BMC Med Ethics 2008; 9: 4.

19 Clayton EW, Ross LF: Implications of disclosing individual results of clinical research. JAMA 2006; 295: 37.

20 Brand A: Public health and genetics - a dangerous combination? Eur J Public Health 2005; 15: 113-116.

21 Bookman EB, Langehorne AA, Eckfeldt JH et al: Reporting genetic results in research studies: summary and recommendations of an NHLBI working group. Am J Med Genet A 2006; 140A: 1033-1040.

22 Affleck P: Is it ethical to deny genetic research participants individualised results? J Med Ethics 2009; 35: 209-213.

23 Beauchamp T, Childress J: Principles of Biomedical Ethics, 5th edn. USA: Oxford University Press, 2001.

24 Fernandez CV, Kodish E, Taweel S et al: Disclosure of the right of research participants to receive research results : An analysis of consent forms in the Children's Oncology Group. Cancer 2003; 97: 2904-2908. 